\title{
The thousand-and-second tale of NFTs, as foretold by Edgar Allan Poe 1
}

\begin{abstract}
Few persons can be made to believe that it is not quite an easy thing to invent a method of secret writing which shall baffle investigation. Yet it may be roundly asserted that human ingenuity cannot concoct a cipher which human ingenuity cannot resolve. ${ }^{2}$
\end{abstract}

It boils down to cryptography. ${ }^{3}$

Everything went virtual in 2020, which may or may not have created the perfect storm for the apparent eruption of non-fungible tokens (NFTs) in the mainstream press. Of course, NFTs had been around for several years before this but, in March 2021, seemingly all of a sudden and everywhere at once, they were occupying almost the entire news cycle. Everything was NFTs, which is not bad for something that is nothing. The application of NFTs has continued with considerable momentum in recent months, with NFTs entering high-profile art markets in sales at the top auction houses, including: Christie's, ${ }^{4}$ who sold Beeple, the first NFT based on an art work $;^{5}$ Sotheby's; ${ }^{6}$ and Phillips. ${ }^{7}$ But NFTs are now well beyond the elite world of contemporary art and moving into the mainstream consumer environments of fashion, ${ }^{8}$ film, ${ }^{9}$ music, ${ }^{10}$ food, ${ }^{11}$ publishing, ${ }^{12}$ and even architecture. ${ }^{13}$ I too am so under their spell,

1. Adapted from the short story by Edgar Allan Poe, 'The Thousand-and-Second Tale of Scheherazade', Godey's Lady Book, January 1845.

2. Edgar Allan Poe, 'A Few Words on Secret Writing', Graham's Magazine, July 1841, 33.

3. D Boscovic, 'How Nonfungible Tokens Work and Where They Get their Value', The Conversation, 31 March $2021<$ https://theconversation.com/how-nonfungible-tokens-workand-where-they-get-their-value-a-cryptocurrency-expert-explains-nfts-157489>.

4. <https://www.christies.com/auctions/christies-encrypted>.

5. <https://www.christies.com/features/Monumental-collage-by-Beeple-is-first-purely-digitalartwork-NFT-to-come-to-auction-11510-7.aspx?sc_lang=en>.

6. <https://www.sothebys.com/en/articles/nfts-redefining-digital-ownership-and-scarcity>.

7. <https://www.phillips.com/press/release/phillips-first-nft-sells-for-41-million>.

8. A Tong, 'Beyond the Bubble: Making NFTs Work for Fashion', Vogue Business, 10 May $2021<$ https://www.voguebusiness.com/technology/beyond-the-bubble-making-nfts-work-forfashion $>$.

9. C Llindahl, 'It's Not a Movie, It's an NFT! How Hollywood is Flirting with the NonFungible Token', IndieWire, 8 April 2021.

10. S Hissong, 'Kings of Leon Will Be the First Band to Release an Album as an NFT', Rolling Stone, 3 March $2021<\mathrm{https}$ ///www.rollingstone.com/pro/news/kings-of-leon-whenyou-see-yourself-album-nft-crypto-1135192/>.

11. V Martino, 'Why NFTs Can Offer Marketing Opportunities for FMCG Brands', Just Food, 21 April $2021<$ https://www.just-food.com/comment/why-nfts-can-offer-marketing-opportunitiesfor-fmcg-brands_id145575.aspx>.

12. P Anderson, 'Germany's Bookwire Announces an NFT Marketplace for Book Publishing', Publishing Perspectives, 6 May $2021<\mathrm{https} / / /$ publishingperspectives.com/2021/05/bookwireannounces-a-blockchain-platform-an-nft-marketplace/>.

13. L Kolirin, 'World's First Digital NFT House Sells for \$500,00', CNN, 24 March 2021 $<$ https://edition.cnn.com/style/article/digital-nft-mars-house-scli-intl/index.html>. 
so to speak, that I have even minted my own NFTs into this article ... in a manner of speaking.

The current excitement has led to a proliferation of commentary and explication (of which this is merely the thousand-and-second), articles teeming with somewhat predictably obligatory references to Walter Benjamin and the age of mechanical reproduction, ${ }^{14}$ frenzied denunciations of any connection between NFTs and art, money, property, and everything in between, met with an almost revelational rhetoric of reverence in their defence. The tale of NFTs is indeed an absurdist one. But it is also a tale of detection. It boils down to cryptography ... and it's a puzzle worth solving. An absurd cryptogram? We need a cryptographer for this strange tale. And who better to ask than Edgar Allan Poe?

\section{THE BALLOON-HOAX}

The Balloon-Hoax is the story of a trans-Atlantic balloon journey 'in the inconceivably brief period of seventy-five hours from shore to shore!' first published in the New York Sun, 13 April 1844, with the headline, 'ASTOUNDING NEWS BY Express, via Norfolk! The Atlantic Crossed in Three Days! Signal Triumph of Mr Monck Mason's Flying Machine! ${ }^{15}$ Its publication led to so much excitement and panic, that it was revealed as a hoax and retracted two days later. ${ }^{16} \mathrm{It}$ is all too seductively part of the puzzle that several commentators have appealed to another ethereal episode, that of Yves Klein selling air in Zone de Sensibilité Picturale Immatérielle, ${ }^{17}$ as the 'first NFT'. ${ }^{18}$ In the ritual of this performance, Yves Klein would present a cheque to the buyer, this would be exchanged for gold, thus acting as payment for air, air in which the cheque is ultimately burned, and half the gold is thrown into the river to be carried away.

So much of the noise around NFTs is preoccupied with their perceived nothingness, faddishness, and technomancy; the apparent inconsequence and untethered explanation for their value - afloat, adrift, and unbound. At the same time, so much of the suspicion and fear betrays a certain nostalgia for traditions of ownership, property, and objects, including the traditions of intellectual property and of money. NFTs and the surrounding

14. W Benjamin, 'The Work of Art in the Age of Mechanical Reproduction' (1955) H Zohn (trans) (1968), Illuminations (Pimlico, 1999) 211-35.

15. Edgar Allan Poe, 'The Balloon-Hoax', The Complete Illustrated Stories and Poems of Edgar Allan Poe (Chancellor Press, 1988) 415.

16. Poe claimed, 'I never witnessed more intense excitement to get possession of a newspaper', quoted in J Meyers, Edgar Allan Poe: His Life and Legacy (Cooper Square Press, 1992 [2000]) 154.

17. <http://www.yvesklein.com/en/oeuvres/view/640/transfer-of-a-zone-of-yyimmaterialpictorial-sensibility-to-m-blankfort-pont-au-double-paris/>.

18. B Franklin, 'Did an Avant-Garde French Artist Sell the First NFT?', The Economist, 29 April $2021<$ https://www.economist.com/1843/2021/04/29/did-an-avant-garde-french-artistsell-the-first-nft>. See further references in B Gopnik, 'The NFT Craze Encapsulates the Absurdity of the Art World - and its Obsession with Authenticity', The Art Newspaper, 1 March $2021<\mathrm{https} / / / \mathrm{www}$.theartnewspaper.com/comment/the-nft-craze-encapsulates-theabsurdity-of-the-art-world-and-its-obsession-with-authenticity>; J Saltz, 'Think of NFTs as a Brush', Vulture, 15 April $2021<$ https://www.vulture.com/2021/04/nfts-will-be-an-artistic-toolas-powerful-as-any-other.html>; A Vikram, 'The NFT's Promise of Control', ARTnews, 5 May $2021<$ https://www.artnews.com/art-in-america/features/artists-nfts-control-market1234591850/>; and D Morris, "II's Chaos for a Lot of People": What is the Future of NFTs in Australian Art?' The Guardian, 18 May $2021<$ https://www.theguardian.com/artanddesign/ 2021/may/19/its-chaos-for-a-lot-of-people-what-is-the-future-of-nfts-in-australian-art>. 
technology have been described variously as alchemy, ${ }^{19}$ snake oil and spin, ${ }^{20}$ and even a hoax. ${ }^{21}$ And far from democratizing the market, the NFT marketplace has been criticized as nothing more than a secret world of nerds, fortune-hunting, and tricks. ${ }^{22}$ As well as confusion over what is being made, what is being sold, and what is being owned, cryptocurrency ${ }^{23}$ itself is notoriously volatile and described as a bubble or a fad, not a permanent development in representative currencies. That one of the newer cryptocurrencies is called Tether $^{24}$ is all too fantastically connected. ${ }^{25}$ Balloons and inflations, indeed. Just another block in the chain.

But in the apparent emergence of NFTs from the elite world of art markets and into the mainstream, the tension between the original work of art and the mass production of consumer markets is persistent. What is the 'original' digital art to which the NFT relates, and what does owning that NFT mean? Is it originality in an idea? Is it ownership in an idea? Or is it all smoke and mirrors and nothing more than a date stamp? A contrivance of digital scarcity? Perhaps the joke is a twice-told tale, an originality in repetition, and this is where the real innovation, not only for art but also for ownership, might be found. Indeed, more than a digital provenance, or artificial scarcity, NFTs refer ownership not to the work, but to the encounter, the ritual, the communication itself. In this way, a multitude of NFTs might relate to one work, but what is reproduced and yet produced anew each time is ownership in the original and unique encounter. In other words, the scarcity is not in the work but in each item of attention on the work. I would therefore disagree that the brand of digital scarcity created by NFTs is somehow at odds with the philosophy of the Internet. ${ }^{26}$ It is immaterial,

19. M Maneker, 'NFTs are Creating the Opposite of Everything They're Meant to Fix', ARTnews, 15 March $2021<$ https://www.artnews.com/art-news/market/nfts-create-opposite-ofeverything-they-are-meant-to-fix-1234586769/>. In this context it seems almost descriptive branding that one of the major start-ups is called Alchemy: <https://www.alchemy.com/nfts $>$. 20. N Hampton, 'Understanding the Blockchain Hype: Why Much of it is Nothing More than Snake Oil and Spin', Computerworld, 5 September $2016<$ https://www2.computerworld.com. au/article/606253/understanding-blockchain-hype-why-much-it-nothing-more-than-snake-oil$\operatorname{spin} />$.

21. S Honarbacht, 'NFT - Is it Art or just a Hoax?', Medium, 7 May $2021<$ https://medium. com/wunderkammer-innovation-and-the-arts/nft-is-it-art-or-just-a-hoax-bfa22dbaa486>.

22. B Allyn, 'What's an NFT? And Why are People Paying Millions to Buy them?', NPR, 5 March $2021<$ https://www.npr.org/2021/03/05/974089381/whats-an-nft-and-why-are-peoplepaying-millions-to-buy-them?t=1622199838980>. Compare technical barriers in C Criddle, 'Buying a Pink NFT Cat was a Crypto Nightmare', BBC News, 30 May $2021<$ https://www. bbc.co.uk/news/technology-57273904>.

23. See further S Ammous, 'Can Cryptocurrencies Fulfil the Functions of Money?' (2018) 70 The Quarterly Review of Economics and Finance 38. Goldman Sachs issued a recent report, which states that 'the mere fact that a critical mass of credible investors and institutions is now engaging with crypto assets has cemented their position as an official asset class': Goldman Sachs, 'Crypto: A New Asset Class?' (2021) 98 Top of Mind 3 <https://www.goldmansachs.com/insights/pages/ crypto-a-new-asset-class-f/report.pdf $>$.

24. <https://tether.to>.

25. In hot air ballooning, the term used to refer to anchoring a balloon to the ground so that it does not fly away is tether: <https://www.brisbanehotairballooning.com.au/balloon-terminology/>.

26. Compare T Nguyen, 'The Value of NFTs, Explained by an Expert', Vox, 31 March, <https:// www.vox.com/the-goods/22358262/value-of-nfts-behavioral-expert>; T Nguyen, 'NFTs, the Digital Bits of Anything that Sell for Millions of Dollars, Explained', Vox, 11 March 2021 $<$ https://www.vox.com/the-goods/22313936/non-fungible-tokens-crypto-explained>. 
quite literally, that Jack Dorsey's tweet is still available, ${ }^{27}$ free as air even. NFTs place the value elsewhere, and bring res familiaris ${ }^{28}$ into play, a sociable property of affiliation and sympathy, as distinct from the rivalrous combat and traditional property lines of objects. As for the object, the NFT is a notice for taking; the objects proliferate because there is nothing for trade but preference. In other words, the competition is for attention - but not on the work or product amidst a sea of objects, as much as it is on the relationship between creator and buyer. Rather than scarcity, the value is generated through an abundance of encounters and an ownership of preferences: 'This image is not an artwork, it is a description of an artwork. The artwork is how you feel when you read this' ${ }^{29}$ No, an NFT is not art, at least not in the conventional, marketable sense. But the ritual may well be.

There have even been arguments over whether NFT is an acronym or an abbreviation. ${ }^{30}$ Does NFT, in the traditional sense of an acronym, spell a word? This is ultimately an argument about meaning, a topic which seems to preoccupy the NFT space, from questions of art right through to value. What does it all mean? But RLLY, between living in LDN and researching in fashion where dropping vowels from BRNDS is SRS business, ${ }^{31}$ the battle for meaning in NFTs is so YSTRDY. As far as branding goes, that NFTs are also known as Nifties, thus returning the vowels, is now making a lot of aporetic sense. ${ }^{32}$ NFTs have become so famous, in every sense of celebrity, that even Sophia the Robot is auctioning work on Nifty Gateway. ${ }^{33}$

As well as non-fungible tokens, the collection of letters, NFT, can refer to time,${ }^{34}$ tangles,${ }^{35}$ tourism, ${ }^{36}$ flourishing, ${ }^{37}$ film,,${ }^{38}$ and, rather appropriately, a venture

27. T Locke, 'Jack Dorsey Sells his First Tweet Ever as an NFT for over \$2.9 million', $C N B C$, 22 March $2021<$ https://www.cnbc.com/2021/03/22/jack-dorsey-sells-his-first-tweet-ever-as-annft-for-over-2point9-million.html>.

28. J Gibson, Owned, An Ethological Jurisprudence of Property (Routledge, 2020) Chapter 12.

29. How you feel, minted by the artist, 7 February $2021<$ https://foundation.app/sterlingcrispin/ how-you-feel-150>.

30. Comment by David nZimmerman, 19 March 2021 at 5.33 pm, on Anthony C, 'Beeple and Nothingness: Philosophy and NFTs', Aesthetics for Birds, 18 March $2021<$ https://aestheticsfor birds.com/author/anthonyc30/>.

31. Editorial, 'British Financial Services Giant ABRDN is Not the Only Company Dropping Vowels', The Fashion Law, 28 April $2021<\mathrm{https} / / /$ www.thefashionlaw.com/british-financialservices-giant-abrdn-is-not-the-only-company-dropping-vowels-from-its-name/>.

32. Especially for one of the more famous digital art-platforms for NFTs, Nifty Gateway $<$ https://niftygateway.com>.

33. <https://niftygateway.com/collections/sophiarobot>.

34. Norfolk Island Time.

35. The appearance of neurofibrillary tangles (NFTs) in the brain is correlated with cognitive disorders (such as Alzheimer's Disease) but causation is less clear, and they may even perform a protective function. S Youssef, 'Pathology of Brain Aging and Animal Models of Neurodegenerative Diseases', in JL Ram and PM Conn (eds), Conn's Handbook of Models for Human Aging (2nd ed, Elsevier, 2018) 899-908.

36. The Not For Tourists series of city guides, published by Simon and Schuster: <https:// www.simonandschuster.com/series/Not-For-Tourists>.

37. Nutrient film technique is a hydroponic system where roots are suspended in a trough of continually recirculating nutrient solution: $\mathrm{N}$ Mattson and J Heinrich Lieth, 'Liquid Culture Hydroponic System Operation', in M Raviv et al. (eds), Soilless Culture: Theory and Practice (2nd ed, Elsevier, 2019) 567 at 570. The continual recirculation is enticingly resonant with the process of NFTs themselves.

38. The National Film Theatre, London. 
capital firm. ${ }^{39}$ In this strange tale these meanings are all seemingly disparate and yet fundamentally related. But it is in another NFT, the Need for Touch, ${ }^{40}$ that the anxieties surrounding concepts of property, ownership, and objects are all too recognizable: 'merely touching an object results in an increase in perceived ownership of that object' ${ }^{41}$ If touch is so particular to the perception of ownership, how might that touch be transfigured within the relationships attributed through NFTs? After all, what are fingers if not digital?

The NFT is thus a network of fancies tied up in one combination of letters and, when it comes to meaning, NFT spells nothing and everything. It is universal and particular all at once. What better way to challenge the linguistic centralization of acronyms than the decentralized worlds of NFTs? Indeed, this very heterogeneity in the meaning of NFT is resonant with the creativity of the concept of ownership mobilized in this marketplace. NFTs are said to make owners of users, ${ }^{42}$ creators of consumers, ${ }^{43}$ and, so it would seem, acronyms of abbreviations.

As for the inflated nature of the hoax? It took some time, but a balloon called Double Eagle II did eventually transport passengers in a crossing of the Atlantic. ${ }^{44}$ All it took was 134 years and two-and-second more days. ${ }^{45}$ So do not write off this tale just yet.

\section{THE PURLOINED LETTER}

The Purloined Letter ${ }^{46}$ is a detective story about a letter hidden in plain sight. The amateur detective, Dupin, follows the logic and morality of play, as in the game of odds and evens, in order to discover that the letter was hidden in the one place the other 'players' would be least likely to look - the open. Poe describes The Purloined Letter as a tale of ratiocination, ${ }^{47}$ a term applied also to The BalloonHoax. ${ }^{48}$ According to Poe, 'These tales of ratiocination owe most of their popularity to being something in a new key. I do not mean to say they are not ingenious - but people think them more ingenious than they are - on account of their method and

39. Noorda Family Trust (NFT Ventures Inc) of Raymond Noorda, former CEO of Novell. 40. 'The NFT is conceptually defined as a preference for the extraction and utilization of information obtained through the haptic system': J Peck and TL Childers, 'Individual Differences in Haptic Information Processing: The "Need for Touch" Scale' (2003) 30 Journal of Consumer Research 430 at 431.

41. J Peck and SB Shu, 'The Effect of Mere Touch on Perceived Ownership' (2009) 36 Journal of Consumer Research 434.

42. C Dixon, 'NFTs and a Thousand True Fans', Andreessen Horowitz, 27 February 2021 $<$ https://a16z.com/2021/02/27/nfts-and-a-thousand-true-fans/>.

43. R Iyengar, 'We Bought an NFT. Here's What We Learned', CNN, 14 March $2021<$ https:// edition.cnn.com/2021/03/14/tech/nft-art-buying/index.html>.

44. <https://airandspace.si.edu/collection-objects/gondola-double-eagle-2/nasm_A1979053 $2000>$.

45. The flight time was 5 days, 17 hours, 5 minutes, 50 seconds: C McCarry, Double Eagle (Little, Brown and Company) vii.

46. First published in The Gift: Christmas, New Year, and Birthday Present (1844).

47. Edgar Allan Poe, Essays and Reviews, GR Thompson (ed) (The Library of America, 1984) 872.

48. See further the discussion in D Ketterer, 'Poe's Usage of the Hoax and the Unity of "Hans Phaall" (1971) 13 Criticism 377. 
air of method'. ${ }^{49}$ The resonance with NFTs, an apparent selling of air, a bubble fit to burst, is all too enticing. As Dupin counsels, 'The material world ... abounds with the very strict analogies to the immaterial'. ${ }^{50}$ By Dupin's own reasoning, how might we start with the phenomenon and reason backwards the significance of NFTs?

During successive lockdowns in this past year of the pandemic, we too have been sequestered, yet hidden in plain sight, and so the appeal of NFTs ballooned 'as a way to have possessions that can be viewed by owners' online friends'. ${ }^{51}$ Thus, it is the value of ownership rather than the value of the owned, the community of sociable properties rather than the alienation of consumer objects, that is at stake here. Cryptocurrencies similarly performed better during the pandemic ${ }^{52}$ and ' $[t]$ he combination of Covid-19 isolation and cryptocurrency profits created a powerful incentive for digital-positive collectors to compete for these NFTs'. ${ }^{53}$

An NFT is thus a kind of purloined letter, ownership laid bare and out in the open. In all the excitement, the content of the letter is remaining largely unread. In a nutshell for tourists, which no doubt describes me as well, NFTs are unique data usually linked to a particular object (such as digital art) and recorded on the blockchain. The blockchain is a form of digital record-keeping in which unique data stored as records, or blocks, are linked through cryptography. This provides for not only the time-stamped recording of each transaction, but also the resilience and reliability of the chain of transactions through the relationships or links between each block. In this way, 'Blockchains allow us to have a distributed peer-to-peer network where non-trusting members can verifiably interact with each without the need for a trusted authority'. ${ }^{4}$ The most widely used blockchain is the permissionless, open-source Ethereum for which the related cryptocurrency is ether (ETH) ${ }^{55}$ However, proprietary blockchains also exist for particular NFT markets, ${ }^{56}$ deviating from the decentralized ethos ${ }^{57}$ and raising further concerns around the lack of regulation in this area. ${ }^{58}$ Nevertheless, the basic decentralized, peer-to-peer operation of blockchains initiates a kind of sociable

49. Edgar Allan Poe, The Letters of Edgar Allan Poe: Volume II, JW Ostrom (ed) (Gordian Press, 1966) 328 (original emphasis).

50. Edgar Allan Poe, 'The Purloined Letter', The Complete Illustrated Stories and Poems of Edgar Allan Poe (Chancellor Press, 1988) 319 at 330.

51. E Howcroft, 'Explainer: NFTs Are Hot. So What Are They?', Reuters, 17 March 2021 <https://www.reuters.com/article/us-crypto-currency-nft-explainer-idUSKBN2B92MA>.

52. For example, see the discussion in R Caferra and D Vidal-Tomás, 'Who Raised from the Abyss? A Comparison between Cryptocurrency and Stock Market Dynamics during the COVID-19 Pandemic' (2021) X Finance Research Letters, advance access.

53. R Prelinger, 'NFTs and AI are Unsettling the Very Concept of History', Wired, 28 April $2021<$ https://www.wired.com/story/nfts-and-ai-are-unsettling-the-very-concept-of-history/>.

54. F Casino et al., 'A Systematic Literature Review of Blockchain-Based Applications: Current Status, Classification and Open Issues' (2019) 36 Telematics and Informatics 55 at 56. 55. <https://ethereum.org/en/>. Ethereum is widely used both privately and commercially. For example, Amazon Managed Blockchain uses the open-source Hyperledger Fabric and Ethereum $<$ https://aws.amazon.com/managed-blockchain/>.

56. For example, NBA Top Shot. See official site: $<$ https://nbatopshot.com>.

57. C Cennamo et al., 'Two Sides of the Same Coin? Decentralized Versus Proprietary Blockchains and the Performance of Digital Currencies' (2020) 2 Academy of Management Discoveries.

58. N Hampton, 'Understanding the Blockchain Hype: Why Much of it is Nothing More than Snake Oil and Spin', Computerworld, 5 September $2016<$ https://www2.computerworld.com. au/article/606253/understanding-blockchain-hype-why-much-it-nothing-more-than-snake-oil$\operatorname{spin} />$. 
approach to property and the generation of value, as distinct from the predatory drift ${ }^{59}$ of conventional property models, including the rivalrous model reiterated in intellectual property. The authority of the record comes not from the sovereignty of a single source, but from the familiar production of the distributed ledger and the replication of the whole chain with every user. ${ }^{60}$ This pooling of resources is not only a feature of blockchain technology, but also confers upon it a distinctly ethological approach to cooperation through shared interests and familiar production. ${ }^{61}$

In this way, the NFT functions as a non-fungible certification in respect of that object and a unique guarantee of ownership in that original object, regardless of how many times it might be replicated. That said, it does not necessarily mean the ownership of any underlying intellectual property in that object. But this is not a phantasm of the digital world; buying any physical expression of a copyright work similarly does not entitle the owner to reproduce the underlying intellectual property. This relationship between owner and object is similar to the unique relationship between the owner and the instance of a unique digital asset as identified by an NFT. Rather than something extraordinary and strange, in many ways the NFT is simply an open acknowledgement of this relationship between owners of objects and the underlying intellectual property - the secrecy of this confusion, exacerbated by the often meaningless refrain of idea and expression, is at last set out in the open.

The NFT may be thus both a record of ownership, rendering that relationship itself non-fungible, and at the same notice for trust, as it were, a testimonial of the genuine object. ${ }^{62}$ Charlie Lee, the creator of the cryptocurrency Litecoin, has been reported widely as asserting that the NFT is not the artwork, it is merely a form of digital certification of authenticity. ${ }^{63}$ But NFTs are more than merely the new art market paperwork, they certify more than the art. An NFT authenticates the relationship between creator, owner, and object. As one NFT artist expressed it, "They approved me, so I officially became an artist"". ${ }^{64}$ In terms of ownership in digital objects, it is therefore more like a claim to ownership rather than a claim to the object, as such. The NFT is a particular instance of the object. What this means is sometimes difficult to translate into an analogue world because it is a relationship that is often misunderstood throughout the history of intellectual property.

Although there are moves to allow conventional payment systems, such as credit cards, NFTs are primarily transacted through cryptocurrencies. Bitcoin remains one

59. J Gibson, Owned, An Ethological Jurisprudence of Property (Routledge, 2020) Chapter 7. 60. See A Sunyaev, Internet Computing: Principles of Distributed Systems and Emerging Internet-Based Technologies (Springer, 2020), particularly 265-99.

61. J Gibson, Owned, An Ethological Jurisprudence of Property (Routledge, 2020) 311-14. On 'shared interests', see Chapter 10.

62. D Boscovic, 'How Nonfungible Tokens Work and Where They Get their Value', The Conversation, 31 March $2021<$ https://theconversation.com/how-nonfungible-tokens-workand-where-they-get-their-value-a-cryptocurrency-expert-explains-nfts-157489>. See further, Charlie Lee in S Dhaliwal, 'Why Crypto Veteran Charlie Lee Is Sounding Alarm Against NFT Craze', Benzinga, 2 March 2021 <https://www.benzinga.com/markets/cryptocurrency/21/ 03/19976209/why-crypto-veteran-charlie-lee-is-sounding-alarm-against-nft-craze>.

63. S Dhaliwal, 'Why Crypto Veteran Charlie Lee Is Sounding Alarm Against NFT Craze', Benzinga, 2 March $2021<\mathrm{https} / / / \mathrm{www}$.benzinga.com/markets/cryptocurrency/21/03/ 19976209/why-crypto-veteran-charlie-lee-is-sounding-alarm-against-nft-craze>.

64. Quoted in R Iyengar, 'We Bought an NFT. Here's What We Learned', CNN, 14 March $2021<$ https://edition.cnn.com/2021/03/14/tech/nft-art-buying/index.html>. 
of the most widely used forms of cryptocurrency ${ }^{65}$ and is an example of a 'proof-ofwork' currency: 'Bitcoin's proof-of-work (PoW) design connects the physical and digital worlds through energy input. PoW interlinks the digital world with the analog world for the first time, resulting in a transparent, verifiable trust network between these worlds. This digital trust tool has profoundly restructured our experience'. ${ }^{66}$ Proof of work thus refers to proof of (computational) effort that is curiously resonant with the kind of 'labour and skill' implied through the narratives of creativity surrounding crypto art. ${ }^{67}$ This 'mining' is referred to as a 'gas fee', which similarly can fluctuate in value within the gamble of the crypto 'game', thus distributing coins by 'creating a game in which miners surrender something valuable - energy - in exchange for the right to claim them' ${ }^{68}$ In this way there is not only a value on the object but also a cost in the transaction, thus emphasizing the substance and value of ownership in and of itself, untethered from the object or thing. ${ }^{69}$

The incentive to play the game resonates with the prevailing discourse in traditional forms of intellectual property - the incentive to produce, the reward for one's labour, and so on. But in this decentralized model of value generation, unlike the predatory competition instilled in conventional approaches to property, arguably the persistent abundance of the objects shifts the perspective from that of dominance to an ethological approach to reinforcement. ${ }^{70}$ Instead of the labour to invest in hiding the letter, it is the odds and evens of fair play that drives the blockchain:

Bitcoin miners sacrifice something valuable (energy) to ensure randomness in who gets to create the next block - a critical component of decentralization ... the distinction is that the energy expended in Bitcoin is $100 \%$ voluntarily committed to the fair play of the game itself - it is the carrot, not the stick. ${ }^{71}$

65. V Combs, 'There's More to Cryptocurrency than Bitcoin: 5 Other Digital Coins to Consider', TechRepublic, 30 April 2021 <https://www.techrepublic.com/article/theres-more-tocryptocurrency-than-bitcoin-5-other-digital-coins-to-consider/>.

66. N Chen, 'Reimagining Beyond Order in Bitcoin', Bitcoin Magazine, 19 April 2021 $<$ https://bitcoinmagazine.com/culture/reimagining-beyond-order-in-bitcoin>.

67. M Jakobsson and A Juels, 'Proofs of Work and Bread Pudding Protocols (Extended Abstract)', in B Preneel (ed), Secure Information Networks (Springer, 1999) 258-72.

68. N Carter, 'The Frustrating, Maddening, All-Consuming Bitcoin Energy Debate', CoinDesk, 5 March $2021<$ https://www.coindesk.com/frustrating-maddening-all-consuming-bitcoin-energy-debate>.

69. This proof of work is also extremely energy-intensive and there is a significant discussion underway to address the environmental impact and sustainability of this system. See G Barber, 'NFTs Are Hot. So Is Their Effect on the Earth's Climate', Wired, 6 March $2021<$ https://www. wired.com/story/nfts-hot-effect-earth-climate/>; P Howson, 'NFTs: Why Digital Art Has Such a Massive Carbon Footprint', The Conversation, 1 April $2021<\mathrm{https} / / /$ theconversation.com/nftswhy-digital-art-has-such-a-massive-carbon-footprint-158077>. Compare the argument that 'energy is not globally fungible' and therefore bitcoin mining actually drives innovation in climate technology research and development: see R Frost, 'Will Clean Energy Help Bitcoin Survive the Green Revolution?' EuroNews, 11 March $2021<$ https://www.euronews.com/green/2021/02/24/ could-renewable-energy-help-bitcoin-clean-up-its-carbon-footprint>; N Chen, 'Reimagining Beyond Order in Bitcoin', Bitcoin Magazine, 19 April $2021<\mathrm{https} / / /$ bitcoinmagazine.com/ culture/reimagining-beyond-order-in-bitcoin >. See also J Truby, 'Decarbonizing Bitcoin: Law and Policy Choices for Reducing the Energy Consumption of Blockchain Technologies and Digital Currencies' (2018) 44 Energy Research \& Social Science 399.

70. J Gibson, Owned, An Ethological Jurisprudence of Property (Routledge, 2020) 259.

71. N Chen, 'Reimagining Beyond Order in Bitcoin', Bitcoin Magazine, 19 April 2021 $<$ https://bitcoinmagazine.com/culture/reimagining-beyond-order-in-bitcoin>. 
Certainty of resources, rather than the scarcity of rewards, becomes an incentive to altruism within a wider understanding of sociable property and production. More on scarcity in a moment, but for now and for this very reason, it is the security of the attribution of every transaction, anonymous or otherwise, that is key. ${ }^{72}$

This play underpinning the blockchain should not be underestimated. Indeed, the very logic of NFTs is said to have emerged through play; that is, in video games through in-game purchases ${ }^{73}$ and behaviours of attachment to digital objects. ${ }^{74}$ Such sociable property relies upon courtesy and the voluntary participation in the game, rather than the coercion of conventional property models. ${ }^{75}$ This proficiency and understanding in bonds and attachment behaviour is seemingly reiterated in the emphasis on pets and the phenomenon of cuteness. ${ }^{76}$ From Cryptokitties ${ }^{77}$ to Dogecoin ${ }^{78}$ Shiba Inu, ${ }^{79}$ and the recent CateCoin, ${ }^{80}$ what is described as starting as jokes ${ }^{81}$ should also be presumed to be continuing as such; but not because the phenomenon should be disregarded ${ }^{82}$ as just nonsense and fairy tales. Rather, this fair play is the morality of the blockchain: 'The coin's value stems from good-humored affinity, a shared sense of being in on a joke'. ${ }^{83}$ And the labour is not only play, ${ }^{84}$ play is also productive work..$^{85}$ As the crypto artist, Pak, invites in his work, The Title: 'Let's play. With value'. ${ }^{86}$

72. J Gibson, Owned, An Ethological Jurisprudence of Property (Routledge, 2020) 251.

73. 'Tokenization of game assets is a real game-changer, since it enables transferring tokens between different games or to another player via NFT specialized blockchain marketplaces': D Boscovic, 'How Nonfungible Tokens Work and Where They Get their Value', The Conversation, 31 March $2021<\mathrm{https}$ ://theconversation.com/how-nonfungible-tokens-workand-where-they-get-their-value-a-cryptocurrency-expert-explains-nfts-157489>.

74. R Watkins and M Molesworth, 'Attachment to Digital Virtual Possession in Videogames' (2012) 14 Research in Consumer Behavior 153.

75. J Gibson, Owned, An Ethological Jurisprudence of Property (Routledge, 2020) 94.

76. 'More recently a new meaning was associated with cats: it includes that they are the symbols of cuteness but overall they are a symbol of the connected community/society that has moulded them': M Benaim, 'From Symbolic Values to Symbolic Innovation: Internet-Memes and Innovation' (2018) 47 Research Policy 901 at 902.

77. <https://www.cryptokitties.co>.

78. <https://www.coinbase.com/price/dogecoin>.

79. <https://shibatoken.com>.

80. <https://www.coinbase.com/price/catecoin>.

81. C Ostroff and C McCabe, 'What Is Dogecoin, How to Say It, and Why It's No Longer a Joke', The Wall Street Journal, 10 May $2021<$ https://www.wsj.com/articles/what-is-dogecoinhow-to-say-it-and-why-its-no-longer-a-joke-thanks-elon-11612820776>; J Summerlad, 'Dogecoin: The Japanese Rescue Dog who became the Unlikely Face of a Crypto Sensation', Independent, 25 May $2021<\mathrm{https://www.independent.co.uk/life-style/gadgets-and-tech/dogecoin-}$ dog-bitcoin-crypto-shiba-b1852891.html>.

82. J Kelly, 'Dogecoin Gives Away the Crypto Game', Financial Times, 11 May 2021 <https://www.ft.com/content/2c3dd96c-b1b1-42fd-ab46-8b4791bf1270>.

83. B Droitcour, 'NFT as Joke', ARTnews, 2 April $2021<\mathrm{https}: / /$ www.artnews.com/art-inamerica/features/nft-joke-1234588596/>.

84. T Nguyen, 'The Value of NFTs, Explained by an Expert', Vox, 31 March $2021<\mathrm{https}: / /$ www.vox.com/the-goods/22358262/value-of-nfts-behavioral-expert>.

85. T Brock and MR Johnson, 'Video Gaming as Craft Consumption' (2021) Journal of Consumer Culture, advance access.

86. <https://niftygateway.com/collections/thetitle>. 


\section{THE GOLD-BUG}

One of Edgar Allan Poe's most famous stories is The Gold-Bug, ${ }^{87}$ a story of secret writing, of cryptography. The tale is a kind of detective story around the deciphering of a cryptogram that promises to lead to the treasure of the genuine historical figure, the infamous pirate, Captain Kidd ${ }^{88}$ Finding the hidden and buried treasure is thus a combination of computational and physical effort, ${ }^{89}$ suggesting that both the cryptogram and the cryptocurrency may function more closely to physical gold than paper money. From one of the greatest storytellers of the supernatural and strange, The Gold-Bug is a mysterious and irresistible precursor for the present fascination with all things crypto - from art to 'money'. But the story is not simply a tale about money. ${ }^{90}$ Rather sympathetically, as it were, it is also Poe's best money-making tale..$^{91}$ Poe had sold the story to the publisher, George Rex Graham, but when Graham did not publish it, Poe sought its return so that he could submit it to a competition in The Dollar Newspaper in $1843 .{ }^{92}$ Poe ultimately won the $\$ 100$ prize, ${ }^{93}$ and circulation of the newspaper exceeded expectations with the enormous success of the story: 'This history of this practical illustration of the poet's cipher theory that human ingenuity cannot construct an enigma human ingenuity cannot resolve, is a further proof of the frequent inability of publishers to gauge the pecuniary value of literary works' ${ }^{94}$ It is a story of money both within and beyond the frame of the literary object.

However, the tale's popularity, accolades, and 'valuation' drew criticism as well, with some labelling it 'unmitigated trash!' for which 'ten or fifteen dollars' would have been ample remuneration 'for this excruciating effort in the tale line'. ${ }^{95}$ The surrounding debate over literary labour, value, and money resonates with the current disquiet over the value of NFTs, both in terms of the perceived levels (or lack) of creative labour in their production, the ethics of their production (particularly with respect to the environmental costs), and the enormous prices being commanded. ${ }^{96}$ Just as Poe lamented the considerable labour in deciphering code, ${ }^{97}$ today that labour is assumed by mining the blockchain, a labour with immense physical cost. The 'labour' of originality is thus the trace of ownership. Authorship in ownership, labour and skill in

87. Edgar Allan Poe, The Gold-Bug (Dana Estes \& Company, 1899). Originally published in The Dollar Newspaper, 1843.

88. c1655-1701.

89. Terence Whalen could have been describing cryptocurrency when he said of Captain Kidd's treasure: 'One of the more obvious differences between paper money and the code is the amount of labor required to realize value': T Whalen, 'The Code for Gold: Edgar Allan Poe and Cryptography' (1994) 46 Representations 35 at 50.

90. Ibid 35 .

91. Poe described it as his 'most successful tale': Edgar Allan Poe, The Letters of Edgar Allan Poe: Volume I, JW Ostrom (ed) (Gordian Press, 1966) 253. But ultimately, 'The bird beat the bug, though' ( $\mathrm{p} 287$, referencing The Raven).

92. JH Ingram, Edgar Allan Poe: His Life, Letters, and Opinions (John Hogg, 1880) 244.

93. EP Oberholtzer, The Literary History of Philadelphia (GW Jacobs \& Co, 1906) 239.

94. JH Ingram, Edgar Allan Poe: His Life, Letters, and Opinions (John Hogg, 1880) 243-4.

95. Daily Forum (Philadelphia) review cited in D Thomas and DK Jackson, The Poe Log: A Documentary Life of Edgar Allan Poe, 1809-1849 (GK Hall, 1987) 420 (original emphases). 96. L Samarbakhsh, 'What Are NFTs and Why Are People Paying Millions for Them?', The Conversation, 17 March $2021<\mathrm{https} / / /$ theconversation.com/what-are-nfts-and-why-are-peoplepaying-millions-for-them-157035>.

97. T Whalen, 'The Code for Gold: Edgar Allan Poe and Cryptography' (1994) 46 Representations 35 at 40-41. 
the blockchain, own intellectual creation, indeed: 'the real secret of a cryptogram is not the concealed message but the social function of secrecy itself' ${ }^{98}$

Poe lived through the tumultuous period of the Bank War in the United States, and many have focused on the impact of the Jackson era on Poe's writing. ${ }^{99}$ The economic depression and Panic of 1837 led to bank suspensions, with a direct impact on publishing and on Poe in particular. ${ }^{100}$ The polarization of specie or hard money (gold and silver) and representative money (bank notes) camps is not dissimilar to debates around cryptocurrency today. The possibility of the manipulation of the cryptocurrency market through large NFT deals has been raised by critics who note also that some of the biggest deals have been funded by digital currency investors in what could be interpreted as 'bidding up your own stock'. ${ }^{101}$ This mixture of fear and loathing around cryptocurrency is curiously reminiscent of the Bank War era of widespread suspicion and scepticism around bank notes, largely due to their perceived volatile and unpredictable value ${ }^{102}$ and their creation out of nothing, ${ }^{103}$ as distinct from the fixed value of gold and silver and the supposed 'intrinsic worth' of hard money: ${ }^{104}$ 'While a coin may be both symbol (as inscription or type) and commodity (as metallic ingot), paper is virtually all symbolic'. ${ }^{105}$ In today's terms, the worth of conventional currency is controlled by State authority, at once tying the debtor to the option of the State; ${ }^{106}$ while cryptocurrency is perceived by some commentators as irrational, fickle, and a kind of religion, ${ }^{107}$ but one seemingly at odds with the sacred meaning of money. ${ }^{108}$

98. Ibid 41.

99. D Faherty, “'A Certain Unity of Design”: Edgar Allan Poe's “"Tales of the Grotesque and Arabesque" and the Terrors of Jacksonian Democracy' (2005) 6 The Edgar Allan Poe Review 4 at 5; and $\mathrm{H}$ Tschachler, The Monetary Imagination of Edgar Allan Poe (McFarland \& Company, 2013).

100. Edgar Allan Poe, The Letters of Edgar Allan Poe: Volume I, JW Ostrom (ed) (Gordian Press, 1966) 121-2.

101. M Elmas, 'The Future of Art, or Just the Latest Cryptocurrency Bubble? NFTs Explained', The New Daily, 27 March $2021<$ https://thenewdaily.com.au/finance/finance-news/2021/03/27/ nfts-art-cryptocurrency-bubble/>.

102. For instance, a recent editorial for Bloomberg maintains that 'cryptocurrency's wild fluctuations say it isn't [money]' and further, that 'Its price is completely disconnected from any practical use', which, it is suggested, renders it otherwise than 'a viable form of money'. See Editorial, 'Whatever Bitcoin Is, It Isn't Acting Like Money', Bloomberg, 21 May 2021 $<$ https://www.bloomberg.com/opinion/articles/2021-05-21/whatever-bitcoin-is-it-isn-t-actinglike-money?sref=ZtdQlmKR>.

103. Tschachler explains, 'to say that paper money also was money meant to accept that something is made out of nothing. According to the gold bugs, this is an achievement that only god and his great opponent were capable of': H Tschachler, The Monetary Imagination of Edgar Allan Poe (McFarland \& Company, 2013) 51.

104. A Schrager, 'Bitcoin is a Lot Like the Art Market', Bloomberg, 21 May $2021<\mathrm{https} / / /$ www.bloomberg.com/opinion/articles/2021-05-21/bitcoin-is-a-lot-like-the-art-market>.

105. M Shell, Money, Language, and Thought (The Johns Hopkins University Press, 1982) 19. 106. J Gibson, The Logic of Innovation (Routledge, 2014) 195.

107. J Authers, 'Bitcoin's Messiahs Share the GameStop Rage', Bloomberg, 21 May 2021 $<$ https://www.bloomberg.com/opinion/articles/2021-05-21/bitcoin-s-messianic-zeal-shares-thegamestop-rage $>$.

108. RW Belk and M Wallendorf, 'The Sacred Meanings of Money' (1990) 11 Journal of Economic Psychology 35. The authors argue that 'money can be sacred and that it is sacralized by certain processes' ( $p$ 35). Notably, 'A further demonstration of the sacredness of money occurs when it is found to be non-fungible' ( $\mathrm{p} 41$ ). 
The culture of cryptocurrency is instead the decentralization of this State 'debt'. Money literally buys nothing. ${ }^{109}$ The debt is infinite. ${ }^{110}$ Cryptocurrencies simply give that realization some momentum and, quite possibly or perhaps implausibly, some accountability: 'Owning bitcoin is the act of adopting full ownership and accountability'. ${ }^{111}$ Recalling the 'trust' ostensibly structured into the relational quality of information on the blockchain, with the freedom to play voluntarily and without regulation, it is claimed that it 'teaches responsibility and nourishes curiosity'. ${ }^{112}$ In The Gold-Bug, similarly "the presence of "trust" ... constitutes a point of mediation between culture and society. Trust is not only essential for economic transactions, including the working of a currency. Trust is also the basis for human bonding, and thus extends to the bond between author and reader'. ${ }^{113}$ It is in this sociable accountability through fair play that the ethological dimension of blockchain becomes particularly interesting, as distinct from the predatory drift of conventional representative money systems. If NFTs keep being referred to as art, it is perhaps because money is not worth the paper it is printed on. Literally. An NFT, on the other hand, suggests a value in and of itself, ${ }^{114}$ through the relationships it facilitates and compels.

As for Captain Kidd's buried treasure, it is a case of 'not paper for paper, but code for gold'. ${ }^{115}$

\section{NEVER BET YOUR HEAD}

The Gold Bug is thus an enticingly fascinating literary precursor to the crypto news of today. But what is the moral of the present tale? Poe mocked the investment in the morals of stories and the belief in the goodness of people in his tale, Never Bet Your Head: A Moral Tale. ${ }^{16}$ What are we to make of the trust at the heart of the blockchain system? Despite Poe's suspicion of these moral tales, it is perhaps the intellectual labour of blockchain that would be attractive: "The most vocal crypto advocates ... believe NFTs can "democratize art" and creative patronage at large'. ${ }^{117}$ Arguably

109. This line comes from the film, Wanderlust (2012), discussed in further detail with respect to debt in J Gibson, The Logic of Innovation (Routledge, 2014) 194-8.

110. On money and the rendering of infinite debt, see J Gibson, The Logic of Innovation (Routledge, 2014) 194-8.

111. N Chen, 'Bitcoin Lurks Where Monetary Responsibility has been Abdicated', Bitcoin Magazine, 24 May $2021<\mathrm{https}$ ///bitcoinmagazine.com/culture/bitcoin-lurks-monetaryresponsibility>.

112. Ibid.

113. H Tschachler, The Monetary Imagination of Edgar Allan Poe (McFarland \& Company, 2013) 64.

114. G Ingham, The Nature of Money (Polity, 2004 [2013]). Ingham contrasts money as a measure of value through the conferral of stability by State authority, with money as a value in itself. 115. T Whalen, 'The Code for Gold: Edgar Allan Poe and Cryptography' (1994) 46 Representations 35 at 49.

116. First published as 'Never Bet Your Head: A Moral Tale', in Graham's Magazine, 1841, but subsequently republished as 'Never Bet the Devil Your Head', in Broadway Journal, 1845. 117. T Nguyen, 'NFTs, the Digital Bits of Anything that Sell for Millions of Dollars, Explained', Vox, 11 March 2021 <https://www.vox.com/the-goods/22313936/non-fungibletokens-crypto-explained>. 
Poe would be amongst this group of enthusiasts: 'Poe portrayed cryptography as something of a democratic art'. ${ }^{118}$ Recalling Poe's A Few Words on Secret Writing, and the lines opening this piece, 'human ingenuity cannot concoct a cipher which human ingenuity cannot resolve'. ${ }^{119}$ Poe explains, 'In the different methods of cryptography ... this complexity is only in shadow. It has no substance whatever. It appertains merely to the formation, and has no bearing upon the solution, of the cipher.' ${ }^{120}$ And as for works of reference, 'the seeker will be disappointed ... he will find nothing upon record which he does not in his own intellect possess'. ${ }^{121}$

But at the same time, Poe also saw cryptography as 'a rare and commercially valuable expression of genius'. ${ }^{122}$ Indeed, the fascination around this kind of contrary perspective on cryptography was a little like the discourse around NFTs and art. In particular, this contradiction subsists in the perceived relationship between NFTs and the traditional discourse of the work of art, and the relationship between mass-produced articles and art more widely, including the 'mass-production' of the digital object. The Gold-Bug is itself concerned with 'The conflict between coded texts and common knowledge', ${ }^{123}$ and Poe's view on cryptography also vacillated between a mass market business model and 'elite practice'. ${ }^{124}$ Similarly, today many are more sceptical of these claims of a more democratic form of social and capital organization through cryptocurrency, with some suggesting the elusion of regulation is a catalyst for another financial crisis: ${ }^{125}$ 'Any currency system which is optimized to fight inflation and act as a store of value is going to preserve and heighten inequalities in the long run. And this is before we talk about relative energy costs and related environmental externalities' ${ }^{126}$ Indeed, this drift towards the more conventional forms of wealth generation and concentration has been identified already in the enormous deals within the art world: '[F]or a technology that promises to "disrupt" the world of digital art, it is tremendously efficient at replicating the most inaccessible paradigms of its physical predecessors'. ${ }^{127}$ Or as one crypto critic put it in relation to music, '[T]he technology is little more than an unfathomably expensive, ridiculously inefficient way to be a music snob'. ${ }^{128}$

118. T Whalen, 'The Code for Gold: Edgar Allan Poe and Cryptography' (1994) 46 Representations 35 at 39.

119. Edgar Allan Poe, 'A Few Words on Secret Writing', Graham's Magazine, July 1841, 33. 120. Ibid 34.

121. Ibid 38 .

122. T Whalen, 'The Code for Gold: Edgar Allan Poe and Cryptography' (1994) 46 Representations 35 at 40.

123. Ibid 46.

124. Ibid 40.

125. R Cooper, 'Will Cryptocurrency Cause the Next Financial Crisis?', The Week, 21 May 2021 <https://theweek.com/articles/983641/cryptocurrency-cause-next-financial-crisis>.

126. Interview with Peter Wolfendale in D Kuhn, 'Why Care About Bitcoin? Here's One Philosopher's Take', CoinDesk, 2 May $2021<$ https://www.coindesk.com/why-care-about-bitcoin-heres-one-philosophers-take>.

127. A Gordon, 'Are NFTs the Future of Digital Music or Just Crypto Snobbery?', Stereogum, 3 March $2021<$ https://www.stereogum.com/2117930/nft-music-blockchain-grimes-3lau/ columns/sounding-board/>.

128. Ibid. 


\section{THE BARGAIN LOST}

Is this a bargain lost? In Poe's story of the same name, later entitled Bon-Bon, ${ }^{129}$ a chef undertakes a Platonic dialogue with the devil, eventually on the question of the soul. But during the exchange, Bon-Bon drinks so much that he is left with uncontrollable hiccups and in attempting to answer the question "'what is the soul?"' is interrupted every time by a hiccup: " $m y$ soul is - hiccup!". ${ }^{130}$

'Indeed! - why it was I who told Aristotle that, by sneezing, men expelled superfluous ideas through the proboscis.'

'Which is - hiccup! - undoubtedly the case,' said the metaphysician, while he poured out for himself another bumper of Mousseux, and offered his snuff-box to the fingers of his visitor. ${ }^{131}$

Is the social contract of the blockchain just a lot of hot air? More bubbles fit to burst and balloons to float away? The key, perhaps, is in the air of method, so to speak, and the nature of that which is 'exhausted' and 'scarce' in the territories of NFTs. Indeed, the element of NFTs that has been celebrated widely in current discussions is that at last a way of producing digital scarcity has been achieved; that is, a way of replicating the rivalrous territories of traditional property within the immaterial relationships of the digital. As Donnie Dinch, CEO of Bitski, ${ }^{132}$ contends: 'Digital ownership, prior to NFTs, is sort of fraudulent and nonexistent'. ${ }^{133}$ In the logic of trust and social bonds, this reference to fraud is notable. The notion is that the infinite can be rendered nominally few and true, but to what end?

\section{THE MAN THAT WAS USED UP}

In The Man That Was Used Up, Poe tells the tale of a war hero whose physical body has been exhausted, quite literally, in its gradual replacement with prosthetic parts. Brevet Brigadier-General John ABC Smith, every man and no man, is no more than 'a large and exceedingly odd-looking bundle of something' which his valet assembles piece by piece as the unnamed narrator 'staggered into an armchair, and, with staring eyes and open mouth, awaited the solution of the wonder'. ${ }^{134}$ The work of the author is exposed as assembled, blocks in a chain, so to speak: 'in an important sense, the authoritative technological objects in ['The Man That Was Used Up'] have themselves been built up through processes of imitation'. ${ }^{135}$

129. The Bargain Lost was the original title for the story, Bon-Bon, in its first published form, Philadelphia Saturday Courier, December 1832.

130. Edgar Allan Poe, 'Bon-Bon', The Complete Illustrated Stories and Poems of Edgar Allan Poe (Chancellor Press, 1988) 732 at 743.

131. Ibid 740.

132. <https://www.bitski.com>.

133. Quoted in T Nguyen, 'NFTs, the Digital Bits of Anything that Sell for Millions of Dollars, Explained', Vox, 11 March 2021 <https://www.vox.com/the-goods/22313936/non-fungibletokens-crypto-explained>.

134. Edgar Allan Poe, 'The Man that Was Used Up', The Complete Illustrated Stories and Poems of Edgar Allan Poe (Chancellor Press, 1988) 465 at 470-71. The story was first published in 1839 in Burton's Gentleman's Magazine.

135. J Berkley, 'Post-Human Mimesis and the Debunked Machine: Reading Environmental Appropriation in Poe's "Maelzel's Chess-Player" and "The Man that Was Used Up" (2004) 41 Comparative Literature Studies, 356 at 363. 
Somewhat ignoring the originality of assemblage, in February, Charlie Lee tweeted that real art takes time and effort to create, and that this is what contributes to the value. ${ }^{136}$ Again, this argument appeals to the language of labour and skill that underpins the 'work' attached to the reasoning of traditional intellectual property. But is this appeal to labour, not only in the 'art' but also in the mining, a confusing nostalgia for a scarcity at odds with the abundance in play, and out of step with a time of innovation no longer up to speed? First, the interpretation of digital scarcity arising in the discourse around NFTs continues to refer back to a traditional scarcity based upon the author, upon the creator; that is, the kind of artificial scarcity contrived within intellectual property systems and the spectre of the romantic author. However, the scarcity model in intellectual property is a notably fickle trick, instating scarcity as a mechanism for consumer desire and a supposed solution to market failure. But the scarcity is actually related to a perceived scarcity in rewards, rather than resources. And the market failure is thus more overtly a failure in incentives to altruism and sociability. Only an abundance of resources is an effective incentive to altruism. ${ }^{137}$ And faith and trust are at the heart of this. ${ }^{138}$

Do NFTs expose this hoax? For NFTs, the scarcity in play is that of the owner, of ownership as non-fungible (as distinct from the object). It is perhaps this seemingly counter-intuitive understanding of scarcity that compels some of the contemporary suspicion of the current 'Bank War': 'Given that anybody can create NFTs, the scarcity of each piece does not guarantee value' ${ }^{139}$ However, it is not just anybody, as is the fundamental reckoning of the blockchain. This is not merely a transaction between anybodies. The key is the relationship, the encounter, between identifiable somebodies. And this ownership not only has a relational value, between creator and buyer, but also mimics traditional property values, whether that is counter-productive or not: 'While anyone can view the NFTs, the buyer has the status of being the official owner - a kind of digital bragging rights' ${ }^{140}$ This creates an interesting disruption of the producer-consumer dynamic, producing a kind of creativity through use, and allowing for an abundance of products where the only competition is for that individual encounter.

But is there anything original about all this?

\section{THE MAN OF THE CROWD}

In The Man of the Crowd, ${ }^{141}$ an unnamed narrator notices a man in the crowd whom he follows for more than a day, finally sitting to face the man, who still does not notice the narrator. The narrator follows and follows, but there is seemingly no limit to this game, no obvious authority, no obvious imitator. The narrator tries to end the game, conclude the story, but in doing so he has relinquished the authority to control the

136. Twitter@SatoshiLite 15 February $2021<$ https://twitter.com/SatoshiLite/status/ 1361188424804311040>.

137. J Gibson, Owned, An Ethological Jurisprudence of Property (Routledge, 2020) 261.

138. B Latour and VA Lepinjay, The Science of Passionate Interests (Prickly Paradigm Press, 2009) 14.

139. E Howcroft, 'Explainer: NFTs Are Hot. So What Are They?', Reuters, 17 March 2021 $<$ https://www.reuters.com/article/us-crypto-currency-nft-explainer-idUSKBN2B92MA>. 140. Ibid.

141. First published in Burton's Gentleman's Magazine, 1840. 
story: 'I grew wearied unto death, and, stopping fully in front of the wanderer, gazed at him steadfastly in the face. He noticed me not, but resumed his solemn walk, while I, ceasing to follow, remained absorbed in contemplation'. ${ }^{142}$ The story thus challenges not only the reliability of the narrator, but also the authority of the author, who is just one of the crowd, just another imitator, just one perspective among many. The narrator is not a romantic ideal, but part of the very thing he is trying to record, just another man of the crowd. And the man of the crowd has made a work of art out of the narrator. Just like NFTs, the game of authorial pursuit makes something out of nothing.

Poe's challenges to the traditional notions of originality are also set out in his criticism as well as his stories, championing the importance of the relationship between author and reader. In a review of Nathaniel Hawthorne's Twice-Told Tales, Poe distinguishes between two forms of originality. The first he describes as the traditional view of originality, which he calls absolute novelty: 'They have limited, in a love for mere words, the literary to the metaphysical originality. They regard as original in letters, only such combinations of thought, of incident, and so forth, as are, in fact, absolutely novel'. ${ }^{143}$ Poe explains that the pleasure of originality comes not from the absolute originality in the combinations of letters in the object, but from 'the novelty of effect' ${ }^{144}$ To recall Sterling Crispin's work, 'This image is not an artwork, it is a description of an artwork. The artwork is how you feel when you read this'. ${ }^{145}$ This is the second form of originality, apparent novelty, which Poe dubs the true originality.

True originality is thus a kind of sociable, relational value produced in concert with the reader:

[T] he true originality - true in respect of its purposes - is that which, in bringing out the halfformed, the reluctant, or the unexpressed fancies of mankind, or in exciting the more delicate pulses of the heart's passion, or in giving birth to some universal sentiment or instinct in embryo, thus combines with the pleasurable effect of apparent novelty, a real egotistic delight. ${ }^{146}$

In this second form of originality, the reader creates through the bond with the author:

$[\mathrm{H}]$ is pleasure is doubled. He is filled with an intrinsic and extrinsic delight. He feels and intensely enjoys the seeming novelty of the thought, enjoys it as really novel, as absolutely original with the writer - and himself. They two, he fancies, have, alone of all men, thought thus. They two have, together, created this thing. Henceforward there is a bond of sympathy between them, a sympathy which irradiates every subsequent page of the book. ${ }^{147}$

They two.

That is, creativity is always already double, and sociable property is always in personam, rather than in res, as it were. The jurist and sociologist, Gabriel Tarde, similarly identifies this sociable and generative quality of sympathy through imitation: 'Sympathy is certainly the primary source of sociability and the hidden or overt

142. Edgar Allan Poe, 'The Man of the Crowd', The Complete Illustrated Stories and Poems of Edgar Allan Poe (Chancellor Press, 1988) 211 at 217.

143. Edgar Allan Poe, Essays and Reviews, GR Thompson (ed) (The Library of America, 1984) 580 .

144. Ibid.

145. How you feel, minted by the artist, 7 February $2021<$ https://foundation.app/sterlingcrispin/ how-you-feel-150>.

146. Edgar Allan Poe, Essays and Reviews, GR Thompson (ed) (The Library of America, 1984) 580-81.

147. Ibid 581 (original emphasis). 
soul of every kind of imitation, even of imitation which is envious and calculating, even of imitation of an enemy'. ${ }^{148}$ Or as Poe asserts, 'The people will imitate the nobles'. ${ }^{149}$ To speak about the art in NFTs, the ownership in NFTs, therefore is not to speak about the object but about the interpretation in that relationship between creator, buyer, and digital object. Thus, the blockchain suggests a kind of ethological interruption to conventional property models that is either all hot air or curiously underestimated.

\section{THE RAVEN}

Poe was notorious for his accusations of plagiarism in other authors. ${ }^{150}$ However, Poe was almost as infamous for his borrowing from other sources, with the most documented example being one of his most well-known works, The Raven. ${ }^{151}$ The narrative poem was so well-loved that the author and the work became interchangeable, ${ }^{152}$ both contested authorities. And the literature surrounding the provenance of The Raven $^{153}$ has become no less interesting than other criticism. But always noted for tricks in his works, Poe's poem not only reveals but also celebrates the sympathy of imitation and the originality in repetition. Throughout the poem the raven is the narrator's interlocutor, imitating human speech, a familiar production through quotation and refrain. In a subsequent essay on composition, in which he uses The Raven as his example, Poe explains:

The fact is, that originality (unless in minds of very unusual force) is by no means a matter, as some suppose, of impulse or intuition. In general, to be found, it must be elaborately sought, and although a positive merit of the highest class, demands in its attainment less of invention than negation. ${ }^{154}$

Poe asserts that, while the lines may have been used before, the originality arises through their combination: 'nothing even remotely approaching this combination has ever been attempted'. ${ }^{155}$

The originality of crypto art is similarly to be found in the scrutiny of provenance, not through authorship as such, but through repeated transactions of relationships, of combinations. The digital art or tweet or kitty attached to an NFT remains abundant and the resources remain seemingly infinite, but the authenticity of each relationship is unique and recorded. The very relationship between author (both creator and consumer) and source thus becomes the object of originality. If, for Poe, 'authorship

148. G Tarde, The Laws of Imitation, EC Parsons (trans) (Henry Holt \& Co, 1890 [1903]) 78 note 8. On sympathy, imitation, and invention, see further, J Gibson, Owned, An Ethological Jurisprudence of Property (Routledge, 2020) 62-4, 91-4, and Part 4: 'Altruism, the Social Age'. 149. Edgar Allan Poe, 'The Philosophy of Furniture', The Complete Illustrated Stories and Poems of Edgar Allan Poe (Chancellor Press, 1988) 715 (original emphasis).

150. For example, see F Galván, 'Plagiarism in Poe: Revisiting the Poe-Dickens Relationship' (2009) 10 The Edgar Allan Poe Review 11.

151. E Richards, 'Outsourcing “The Raven”: Retroactive Origins' (2005) 43 Victorian Poetry 205. 152. Kenneth Silverman states, 'Poe's own fame rose with that of "The Raven," and many readers identified poet and poem': K Silverman, Edgar A Poe: Mournful and Never-Ending Remembrance (Harper Perennial, 1991) 238.

153. First published in Graham's Magazine, 1845.

154. Edgar Allan Poe, 'The Philosophy of Composition', Graham's Magazine, 1846, 163 at 166. 155. Ibid. 
and originality are some form of outsourcing, ${ }^{156}$ it is as for NFTs, originality in the repetition of ownership.

This tension between the sovereignty of the creator and the authority of the buyer runs through one of Christie's more recent NFT auctions, Proof of Sovereignty, a collaboration with Lady PheOnix 'to bring together over 20 new media artists experimenting with blockchain technology'. ${ }^{157}$ In doing so, the auction catalogue emphasizes not only the objects or works, but also the technical alterity of the process, stating that the curation 'employs metadata, storage, and legal standards that have been virtually absent from millions of artworks associated with non-fungible tokens until now'. ${ }^{158}$ The work that was used up and radically displayed, both disputing and proving the sovereignty of the work all at once. Returning to the 'friendships' of the blockchain, the trust is not to be found in the sovereignty of a single authority but in the familiar production of community, the res familiaris of the series of quotations and encounters.

Quoth the Raven.

\section{PINAKIDIA}

In the style of familiar production, Poe published a collection of notes and marginalia under the title, Pinakidia, an extensive inventory of " Random Thoughts," "Odds and Ends," "Stray Leaves," "Scraps," "Brevities," and a variety of similar titles'. ${ }^{159}$ In doing so he notes the 'outsourcing' in such notes, which 'are either piecemeal cullings at second hand, from a variety of source hidden or supposed to be hidden, or more audacious pilferings from those vast storehouses of brief facts, memoranda, and opinions in general literature'. ${ }^{160}$ A cryptography of authorship, sources ordinarily hidden are thus set out in full in a landscape of provenance, as it were. What appears is again the sociable knowledge of authorship, with an emphasis on community in knowledge, not unlike the new familiar tenure of fandoms in the world of NFTs. Recalling The Gold-Bug and its secret writing 'of transmitting information from one individual to another in such manner as to elude general comprehension', ${ }^{161}$ Pinakadia links the blocks of sources and exposes them for all to see, placing the reader and the creator on an equal footing, so to speak, with the author.

There is a curious sentence in Poe's introduction to the collection, where he states, 'Most of the following is original, and will be readily recognized as such by the classical and general reader'. ${ }^{162}$ At first blush it would appear that a 'not' is missing, and this has even been corrected by some Poe scholars as a typographical error, with some reproductions of the text inserting '[not]' before 'original'. ${ }^{163}$ But is it really an error? Most of the

156. F Gutbrodt, Joint Ventures: Authorship, Translation, Plagiarism (Peter Lang, 2003) 262. 157. <https://onlineonly.christies.com/s/proof-sovereignty-curated-nft-sale-lady-pheonix/ overview/2058>.

158. Ibid.

159. Edgar Allan Poe, 'Pinakidia', Southern Literary Magazine, August 1836, 573-82 at 573. 160. Ibid.

161. Edgar Allan Poe, 'A Few Words on Secret Writing', Graham's Magazine, July 1841, 33. See further T Whalen, 'The Code for Gold: Edgar Allan Poe and Cryptography' (1994) 46 Representations 35 at 51 .

162. Edgar Allan Poe, 'Pinakidia', Southern Literary Magazine, August 1836, 573-82 at 574. 163. EL Griggs, 'Five Sources of Edgar Allan Poe's "Pinakidia"' (1929) 1 American Literature 196. For example, see The Edgar Allan Poe Society of Baltimore <https://www.eapoe.org/works/ misc/pnkdia.htm>. See further, GE Woodberry, Edgar Allan Poe (Houghton Mifflin, 1885) 96. 
following is original to the cited authors and, recalling Poe's originality in combination, original to Poe as well. Pinakidia appears to be a remarkable predestination of the tale of NFTs.

In Pinakidia, Poe seemingly introduces himself as a man of the crowd, and realizes long before the scholarship on fandoms the kind of kinship and community achieved through shared sources and intertextuality. Similarly, the NFT market operates on an abundance of the object towards the production of 'A new digital family' 164 through a community of sociable knowledge and encounters with and through the object. ${ }^{165}$ Even if registries were "flooded with blockchain-authenticated look-alikes and deepfakes', ${ }^{166}$ it is arguably irrelevant, or at the very least beside the point, as the authenticity of the NFT is in the relationship, not the product. The logic of fandoms informs not only the trust but also the value, and 'fan-driven industries are recognizing the technology's potential as a burgeoning revenue stream' ${ }^{167}$ The 'need for touch' is thus fulfilled in the individual encounter and the market scarcity of ownership: "I don't really buy for investments too much. In most cases, most of the art I own is because I want to appreciate someone's work and say 'hey, great stuff, I'm a fan,' and buy it"'. ${ }^{168}$ And all it takes is a few dedicated fans. ${ }^{169}$

It is in this respect that the ledger of ownership and royalties with each successive sale mean that the creator and object are forever linked in a relationship with owners. Terry Nguyen notes that: 'Artists and musicians have historically relied on middlemen auction houses, galleries, and streaming platforms - to sell or host their work. In some cases, they don't earn royalties from future sales'. ${ }^{170}$ The 'need for touch' might be read into the need to 'exchange contracts and ensure that money changes hands' in order for 'layers of middlemen to establish trust in the transaction'. ${ }^{171}$ 'With NFTs, artists can ensure that they receive a predetermined share of royalties (usually 10 percent) from sales on the secondary market'. ${ }^{172}$ Chris Dixon, a partner with the venture capitalist firm, Andreessen Horowitz, describes NFTs as providing a fairer economic

164. R Iyengar, 'We Bought an NFT. Here's What We Learned', CNN, 14 March $2021<$ https:// edition.cnn.com/2021/03/14/tech/nft-art-buying/index.html>.

165. For instance, see the Twitter feed, Bitcoin Starter Pack (@bitcoinnico) and N Chen, 'Reimagining Beyond Order in Bitcoin', Bitcoin Magazine, 19 April $2021<\mathrm{https} / / /$ bitcoin magazine.com/culture/reimagining-beyond-order-in-bitcoin $>$ where the author explains Bitcoin through Jordan Peterson's Beyond Social Order (Allen Lane, 2021).

166. R Prelinger, 'NFTs and AI are Unsettling the Very Concept of History', Wired, 28 April $2021<\mathrm{https} / / / \mathrm{www}$.wired.com/story/nfts-and-ai-are-unsettling-the-very-concept-of-history/>.

167. T Nguyen, 'NFTs, the Digital Bits of Anything that Sell for Millions of Dollars, Explained', Vox, 11 March 2021 <https://www.vox.com/the-goods/22313936/non-fungibletokens-crypto-explained>.

168. Pet3rpan quoted in R Iyengar, 'We Bought an NFT. Here's What We Learned', CNN, 14 March $2021<$ https://edition.cnn.com/2021/03/14/tech/nft-art-buying/index.html>.

169. K Kelly, '1000 True Fans', The Technium, 4 March 2008 (updated version) <https://kk. org/thetechnium/1000-true-fans/>.

170. T Nguyen, 'NFTs, the Digital Bits of Anything that Sell for Millions of Dollars, Explained', Vox, 11 March 2021 <https://www.vox.com/the-goods/22313936/non-fungibletokens-crypto-explained>.

171. J Bowden and ET Jones, 'NFTs are Much Bigger than an Art Fad - Here's How They Could Change the World', The Conversation, 26 April $2021<\mathrm{https}$ ://theconversation.com/ nfts-are-much-bigger-than-an-art-fad-heres-how-they-could-change-the-world-159563>.

172. T Nguyen, 'NFTs, the Digital Bits of Anything that Sell for Millions of Dollars, Explained', Vox, 11 March $2021<$ https://www.vox.com/the-goods/22313936/non-fungibletokens-crypto-explained>. 
environment for creators in three ways. First, 'by removing rent-seeking intermediaries ... blockchain-based ownership shifts the power back to creators and users' ${ }^{173}$ Second, 'NFTs change creator economics ... by enabling granular price tiering', ${ }^{174}$ a kind of usage-based model of pricing that is facilitated by the fandom or community imagined through NFTs. At the same time, however, I would argue that NFTs also capture value, but not in the object, as such; rather, in the relationship through the economics and affiliative culture of fandom: 'There is an inherent feeling of community'. ${ }^{175}$ Finally, Dixon argues that NFTs make owners out of users, 'thereby reducing customer acquisition costs to near zero'. ${ }^{176}$ On the surface this makes sense, but it now appears this is not as simple, or even as banal, as making users into owners; rather, ownership is recast through relational qualities of use. The 'need for touch' so to speak, is sustained through the relationship between creator and buyer, and the link between creator and object, made permanent almost collaterally or incidentally because the link between maker and buyer is maintained: 'It matters to the player where she got the shield'. ${ }^{177}$ The ritual of Yves Klein's air now seems clear as day.

\section{X-ING A PARAGRAB}

One of the last stories Poe wrote was X-ing a Paragrab, ${ }^{178}$ an extraordinary account of the issues at hand and a fitting circularity to this tale of NFTs and nifties, letter for letter, as it were. This is the tale of Mr Touch-and-go Bullet-head who leaves 'that legitimate home for all wise men, the East,' to migrate to 'the city of Alexander-theGreat-o-nopolis, or some place of a similar title, out West' and attempts to establish a newspaper, The Tea-Pot, on the mistaken belief that the town has no newspaper. However, already established is the Alexander-the-Great-o-nopolis Gazette, and a bitter publishing rivalry ensues. The need for Touch-and-go, so to speak, to establish his paper prompts a leading article of puffery, awash with exclamations. The Gazette responds with 'Why, the fellow is all $\mathrm{O}$ ! That accounts for his reasoning in a circle, and explains why there is neither beginning nor end to him, nor to anything he says'. ${ }^{179}$ In retaliation, Touch-and-go publishes an Editorial where the only vowels used are Os, a vision of nothingness. But when the time comes to set it for print, "Not a single little- $o$ was in the little- $o$ hole' and 'the capital-O partition' was 'in a precisely similar predicament'. ${ }^{180}$ Without any Os the only solution is 'to $x$ this

173. C Dixon, 'NFTs and a Thousand True Fans', Andreessen Horowitz, 27 February 2021 $<$ https://a16z.com/2021/02/27/nfts-and-a-thousand-true-fans/>.

174. Ibid.

175. FEWOCiOUS, attributed in T Nguyen, 'NFTs, the Digital Bits of Anything that Sell for Millions of Dollars, Explained', Vox, 11 March $2021<$ https://www.vox.com/the-goods/ 22313936/non-fungible-tokens-crypto-explained>.

176. C Dixon, 'NFTs and a Thousand True Fans', Andreessen Horowitz, 27 February 2021 $<$ https://a16z.com/2021/02/27/nfts-and-a-thousand-true-fans/>.

177. Matt Stephenson quoted in T Nguyen, 'The Value of NFTs, Explained by an Expert', Vox, 31 March 2021, <https://www.vox.com/the-goods/22358262/value-of-nfts-behavioral-expert>.

178. First published in Flag of Our Union, 12 May 1849.

179. Edgar Allan Poe, 'X-ing a Paragrab', The Complete Illustrated Stories and Poems of Edgar Allan Poe (Chancellor Press, 1988) 473 at 474.

180. Ibid 475. 
ere paragrab', ${ }^{181}$ a vowel of uncertain value. When the paragraph is published with all the Os replaced by Xs, readers are scandalized and rush to find Touch-and-go, only to discover he has vanished: 'Even the town mathematician confessed that he could make nothing of so dark a problem. X, everybody knew, was an unknown quantity; but in this case (as he properly observed), there was an unknown quantity of $X^{\prime}{ }^{182}$

Poe's humorous criticism of the unproductive rivalries in publishing should not go unnoticed. Here and throughout his writings, Poe continued to challenge the commodification of literary labour as object, as distinct from nourishing it as an abundant resource in order to turn it into 'a productive force that could expand without limit'. ${ }^{183}$ In the present excitement, NFTs are a kind of paragrab, a sideways move, a displacement of value from the object to elsewhere. Like O, NFTs are charged with nothingness and, at the same time, infinite self-equivalence. NFTs too are both celebrated and remonstrated for making something out of nothing. But in the work of ownership, the property has 'neither beginning nor end'.

What then, is the next frontier - tangible? ${ }^{184}$ More interesting than whether NFTs will or can move to the physical world is whether value might move from the physical world to the 'digital' world of relations, and the linear model of creativity might become a more cooperative affair between creator and owner.

They two. And the many others as well.

Johanna Gibson

1 June 2021

181. Ibid 476.

182. Ibid 477.

183. T Whalen, 'The Code for Gold: Edgar Allan Poe and Cryptography' (1994) 46 Representations 35 at 51.

184. For example, Nike's US Patent No US10505726B1 'System and method for providing cryptographically secured digital assets' which includes 'cryptographic digital assets for articles of footwear, methods for making/using such cryptographic digital assets, and decentralized computing systems with blockchain control logic for mining, intermingling, and exchanging blockchainenabled digital shoes'. 